\title{
Impact of Hepatitis B Virus (HBV) Vaccination in Childrens Born to HBV Positive Mothers
}

\author{
Dhevahi Elumalei ${ }^{1}$, S.Saravanan, R.Parthiban, Nayak $\mathrm{HK}^{2}$, Malathi $\mathrm{S}^{3}$, \\ Thyagarajan S.P ${ }^{1}$ \\ Department of Microbiology, Dr. A.L.M. PGIMS ${ }^{1}$, \\ National Institute of Epidemiology Chetpet ${ }^{2}$, \\ Institute for Child Health, Egmore Chennai ${ }^{3}$.
}

\begin{abstract}
Perinatal HBV transmission is common in South East Asia approximately 25-30\% of the carrier pool. The problem is not only to the mother but also pertains to the offspring, in pregnancy hepatitis; the immune alterations in pregnancy may modify the dynamics of the disease. The infants of the mothers, who are carrying both HBsAg and HBeAg, have the highest risk of acquiring the HBV infection by the perinatal route. The over all risk may vary from one population to another, depending on the prevalence of HBeAg positivity in the pregnant women. It is reported and estimated that 22,000 pregnant women in the United States get infected with hepatitis $B$ virus, which necessitated hepatitis $B$ vaccination of the newborn mandatory in the United States.

This study was aimed to bring about authenticated documentation on impact of preventive measures by vaccination that are essential features to plan and implement health measures package in a country.

Results: Inspite of neonatal vaccination against hepatitis B given to all 158 children born to their $\mathrm{HBsAg}$ positive mothers, $6.8 \%$ (6/87) of these infants reached the status of chronic HBV infection from their infected mothers after 12 months follow-up.
\end{abstract}

Conclusion: $6.8 \%$ (6/87) of the infants developed chronic HBV infection in spite of hepatitis B vaccination all the children by acquiring $H B V$ from their infected mothers as confirmed by twelve months of follow-up.

Keywords: Perinatel, vertical transmission; screening; hepatitis B; intrauterine infection, Viral Hepatitis, Hepatitis $B$ virus

\section{Introduction}

Viral hepatitis is the most common cause of jaundice in pregnancy. Perinatal transmission from mothers infected with HBV (i.e. positive for $\mathrm{HBsAg}$ ) to the newborn infants is a major source of HBV infections in many countries. Three possibilities of transmission of HBV from carrier mothers to infants are suggested (a) transplacental transmission of HBV in utero (antenatal transmission), (b) natal transmission during delivery; (c) postnatal transmission from mother to infants during childcare or through breast milk (Schweitzer et al., 1972; Anderson et al., 1975). In pregnancy hepatitis, the immune alterations in pregnancy may modify the dynamics of the disease. The problem is not only to the mother but also pertains to the offspring. The risk for the mother includes development of acute liver failure or fulminant hepatitis characterized by encephalopathy with or without coagulopathy. (WHO, 2001) Till date, published reports from South India have documented $\mathrm{HBV}$ as the major causative agent of viral hepatitis in the adults and children in general. It is reported and estimated that 22,000 pregnant women in the United States get infected with hepatitis B virus, which necessitated hepatitis B vaccination of the newborn mandatory in the United States. Perinatal HBV transmission is common in SouthEast Asia. The infants of the mothers, who are carrying both HBsAg and $\mathrm{HBeAg}$, have the highest risk of acquiring the $\mathrm{HBV}$ infection by the perinatal route. It has been estimated that in Asia, perinatal transmission accounts for approximately 25-30\% of the carrier pool. (CDC, 1996). The over all risk may vary from one population to another, depending on the prevalence of HBeAg positivity in the pregnant women.

With this background information, this study was aimed to bring about authenticated documentation on impact of preventive measures by vaccination that are essential features to plan and implement health measures package in a country.

\section{Materials and Methods}

158 infants born to HBV positive asymptomatic mothers were screened for HBV infection markers at birth. 87 completed the one year period of vaccination and were analyzed for the study. The follow up visits were scheduled at 3 monthly intervals until the infants were 12 months old. Strict adherence to the follow-up 
schedule was maintained; every mother was asked to return within 3 days of the target date and those who did not, were visited at their homes by Field visitors, Microbiologist and Clinician.

All the babies born to Asymptomatic HBsAg positive mothers received three $0.5 \mathrm{ml}$ each doses of Hepatitis B vaccine by intramuscular injection in the lateral aspect of the thigh. At birth, as first dose second dose at 1 month after birth and the third dose at sixth month after birth.

\section{Results}

87 Mother / Child pairs completed one year follow up and were analyzed for vertical / perinatal transmission of $\mathrm{HBV}$ inspite of $\mathrm{HBV}$ vaccination.

$6.8 \%$ (6/87) of these infants reached the status of chronic HBV infection from their infected mothers after 12 months follow-up. Of these 3 infants were born to HBeAg and HBV-DNA positive mothers and continued to be positive for HBsAg from birth till $12^{\text {th }}$ month. Simultaneously, three other infants who were negative for HBsAg from birth till $2^{\text {nd }}$ month became positive for HBsAg at $3^{\text {rd }}$ month and continued to be positive till $12^{\text {th }}$ month. Of these three infants, one was borne to HBsAg positive HBeAg / anti-HBe negative mother and 2 were borne to anti-HBe positive mothers. All these mothers were HBV-DNA positive.

\section{Discussion}

Rate of chronic HBV infection in infants increases with maternal virus load. Children born to HBeAg / HBV-DNA positive mothers are said to have greater risk of acquiring HBV if no vaccine is given at birth. Even with vaccine it is said that the exposure of infants with immature immune system the large quantities of viral DNA may contribute to their inability to resolve HBV infection (Robert et al., 1994).

In the present study a 12-month follow-up of children born to hepatitis B positive mothers, given full course of vaccination resulted in six of the infants acquiring HBV inspite of completing the vaccination process. Analysis of HBV marker profile of the markers who have transmitted the virus to the infants the following.

1) Of the six infants who had acquired HBV, 3 of them were born to HBeAg positive mothers (3/22- 13.6\%) and (2/65-3\%) and one was born to a mother who was negative for HBeAg and anti -HBe but positive for HBsAg alone.

2) Further analysis of the HBV-DNA status of this mother's who have transmitted HBV to their infants has shown that all of them were HBV-DNA positive.

Wheeley et al., (1990) reported that $3 / 8$ infants who had received HBIG along with vaccine acquired $\mathrm{HBV}$ infection. Ip et al (1989) showed 25\% babies born to HBeAg positive mothers became infected by HBV when hepatitis B vaccine alone was given and $10-15 \%$ of those in spite of giving HBIG at birth.

These observations confirm the hypothesis of Burk et al., (1994) who have stated that the quantity of HBV in terms of concentration of circulating maternal viral DNA to which the infants are exposed is likely to decide the occurrence of chronic carrier state in the infants born to them.

It is amazed that the children born to $\mathrm{HBeAg}$ positive and HBV-DNA positive mothers may have to be given both hepatitis B vaccine and HBIG immediately after birth to obtain 100\% success rate in preventing perinatal transmission.

Active vaccination has remained as the most effective way to control hepatitis B virus. Administration of vaccine immediately after birth is effective in preventing the transmission from a hepatitis B e antigenpositive mother in approximately $70 \%$ of cases. This rate may be increased to greater than $90 \%$ if the vaccine is accompanied by simultaneous administration of hepatitis B immunoglobulin (HBIG) (Wheeley et al., 1985; Stevens et al., 1987).

\section{Conclusion}

Among the Mother / Child pairs analysed, 6.8\% (6/87) of the infants developed chronic HBV infection in spite of hepatitis B vaccination all the children by acquiring HBV from their infected mothers as confirmed by twelve months of follow-up. The aim of the study is to bring about authenticated documentation on pregnancy hepatitis, maternal and fetal outcome in pregnancy hepatitis, transmission pattern from mother to child in asymptomatic viral infected mothers and impact of preventive measures by vaccination that are essential features to plan and implement health measures package in a country, Such comprehensive documentation are generally not available in developing countries and especially in India.

\section{References}

[1]. Schweitzer JL, Wing a. and PetersR.I. Viral Hepatitis and HAA in 56 mother infants. Am.J.Med Assoc. 1972;220:1092-1095

[2]. Anderson K.E., Stevens, C.E., Tsuei J.J, Lee, W.C., Sun., T. and Beasley R.P.

[3]. Australian antigen in infants born to mothers with chronic Australian antigenaemia in Taiwan. American J. Disease Child 1975; 129:1389-1392.

[4]. WHO: Department of Vaccines and Biologicals: Introduction of Hepatitis B Vaccine into Childhood Immunization Services.(World Health Organisation Geneva) 2001: 1-55. 
[5]. Center for Disease Control (CDC): Clinical discussions-Hepatitis and other liver diseases during pregnancy 1996;4 (1): 1-4

[6]. Robert et al., Outcome of perinatal HBV exposure is dependent on Maternal Virus load. JID 1994; 170:1418-1423.

[7]. Wheeley et al., Hepatitis B vaccine in the prevention of perinatally transmitted hepatitis B virus infection. Final report of West Midlands pilot study. J Med Vir.1990;30:113-116

Table - I

Mother /Child Followed Up Analysis Among The Children Born To HBV Positive Pregnant Women

\begin{tabular}{|c|c|c|c|c|c|}
\hline Current follow-up & $\begin{array}{c}\text { No. of Mother } \\
\text { sample } \\
\text { analysed }\end{array}$ & $\begin{array}{c}\text { Mother- } \\
\text { HBsAg pos } \\
\text { status. }\end{array}$ & \multicolumn{2}{|c|}{$\begin{array}{c}\text { Baby } \\
\text { sample } \\
\text { analysed }\end{array}$} & \multicolumn{2}{|c|}{ Children HBsAg } \\
Pos & 158 & 158 & 14 & 8.8 \\
\hline Delivery & 158 & 158 & 158 & 12 & 7.6 \\
\hline 2 month After Birth & 158 & 149 & 149 & 6 & 4 \\
\hline 3- month After Birth & 149 & 118 & 118 & 6 & 5 \\
\hline 6 month After Birth & 118 & 91 & 91 & 6 & 6.5 \\
\hline 9 month After Birth & 91 & 87 & 87 & 6 & 6.8 \\
\hline 12 month After Birth & 87 & & & & \\
\hline
\end{tabular}

Table- II

HBsAg Positivity In Children Born To HBV Carrier Mothers And Their Details Of Vaccination

\begin{tabular}{|l|c|c|c|}
\hline \multirow{2}{*}{} & \multicolumn{3}{|c|}{ Follow up samples at 12 } \\
& \multicolumn{2}{|c|}{ month } \\
\cline { 2 - 4 } & No. Analysed & $\begin{array}{c}\text { No. } \\
\text { Pos. }\end{array}$ & $\%$ \\
\hline Vaccine and HBIg & 7 & 0 & 0 \\
\hline Vaccine Immediately after birth & 12 & 0 & 0 \\
\hline Vaccine given between (2-7 days) & 68 & 6 & 8.8 \\
\hline
\end{tabular}

